\title{
ESTÁGIO DE COLHEITA E SUBSTRATO PARA O TESTE DE GERMINAÇÃO DE SEMENTES DE IPÊ (Tabebuia chrysotricha (Mart. ex DC.) Standl.) ${ }^{1}$
}

\author{
Cibele Chalita Martins², Adriana Martinelli-Seneme ${ }^{3}$ e João Nakagawa²
}

\begin{abstract}
RESUMO - Durante o processo de maturação, as sementes passam por modificações físicas, bioquímicas e fisiológicas até atingir o ponto ideal de colheita, quando apresentam a capacidade máxima de germinação e vigor. O objetivo deste trabalho foi identificar o estágio de colheita e o substrato mais favorável à germinação das sementes e ao crescimento de plântulas de Tabebuia chrysotricha. Os frutos de T. chrysotricha foram colhidos em 16 árvores- matriz na Fazenda Lageado, em Botucatu, SP, em quatro estágios de colheita: fruto fechado menor (ME), fruto fechado maior (MA), fruto em início de abertura (IA) e fruto aberto e em início de dispersão das sementes (D). Para caracterizar os estágios de colheita, foi utilizada a coloração dos frutos e das sementes, mensurados a espessura, a largura e o comprimento dos frutos e determinado o teor de água das sementes. O efeito do estágio de colheita sobre a qualidade das sementes foi verificado mediante o teste de germinação sobre areia e sobre papel a $25^{\circ} \mathrm{C}$, avaliado após 21 dias da semeadura; e o vigor, pelo teste da primeira contagem (7 dias) e do comprimento de plântulas (21 dias). Os resultados indicaram que as sementes de Tabebuia chrysotricha devem ser colhidas quando o fruto estiver em início de abertura. Este estágio de colheita também pode ser identificado pelo teor de água das sementes de 59,6\%. O substrato areia mostrou-se mais favorável ao teste de germinação e ao crescimento das plântulas.
\end{abstract}

Palavras-chave: Tabebuia chrysotricha, ponto de colheita e substrato.

\section{HARVEST STAGE AND SUBSTRATUM FOR IPE (Tabebuia chrysotricha (Mart. ex DC.) Standl.) SEED GERMINATION TEST}

\begin{abstract}
Seeds undergo physical, biological and physiological changes during their maturation process until reaching the ideal harvest time, presenting maximum germination capacity and vigor. The objective of this work was to identify the most favorable harvest stage and substratum for seed germination and seedling growth of Tabebuia chrysotricha. Fruit of T. chrysotricha were harvested from 16 matrix trees at Lageado Farm, Botucatu-SP, Brazil, at four harvest stages: smaller closed fruit, larger closed fruit, open starting fruit, and opened fruit with dispersal starting seeds. The harvests stages were characterized by color of fruits and seeds, width, thickness and length of fruits and water content of seeds. The effect of the harvest stage on seed quality was evaluated by germination test carried out on sand and paper, at $25^{\circ} \mathrm{C}$, final count performed 21 days after sowing, and vigor by the first count of germination test ( $7^{\text {th }}$ day) and seedling length (at 21 days). The results showed that T. chrysotricha seeds must be harvested when fruit start to open; this particular harvest stage could also be identified by the water content of seeds (59.6\%); and that sand substratum was more favorable to seed germination and seedling growth than paper.
\end{abstract}

Keywords: Tabebuia chrysotricha, harvest time and substratum.

\footnotetext{
${ }^{1}$ Recebido em 14.08.2006 e aceito para publicação em 15.12.2007.

${ }^{2}$ Departamento de Produção Vegetal da Universidade Estadual Paulista Júlio de Mesquita Filho(UNESP), . E-mail : <cibele@fca.unesp.br> e $<$ secdamvfcaunesp.br $>$.

${ }^{3}$ Faculdades Integradas Espírita (FACIBEN), Curitiba-PR . E-mail : <amseneme@ufpr.br>.
} 


\section{INTRODUÇÃO}

Tabebuia chrysotricha (Mart. ex DC.) Standl., conhecida como ipê-amarelo-cascudo, ipê-do-morro, ipê, ipê-amarelo, aipé, ipê-tabaco, é uma árvore decídua, heliófita, que ocorre na Floresta Pluvial Atlântica do Brasil, nos Estados do Espírito Santo até Santa Catarina. A espécie é utilizada, principalmente, em arborização de ruas devido ao seu florescimento intenso de cor amarela na planta sem folhagem e ao pequeno porte, pois a árvore adulta apresenta de 4 a $10 \mathrm{~m}$ de altura e tronco de 30 a $40 \mathrm{~cm}$ de diâmetro. Essa espécie floresce nos meses de agosto a setembro, e o período de maturação das sementes é curto, se comparado com o de outras espécies florestais nativas. A dispersão anemocórica das sementes ocorre nos meses de setembro a outubro (LORENZI, 1992).

Durante o processo de maturação, as sementes passam por modificações físicas (tamanho, coloração e teor de água), bioquímicas (açúcares, proteínas, óleo, ácidos graxos) e fisiológicas (germinação, vigor, massa seca). Essas modificações são influenciadas por fatores genéticos e ambientais até atingir o ponto de maturidade fisiológica, que é o ponto de máxima qualidade fisiológica da semente, quando estas apresentam o máximo de germinação, vigor e massa seca. A identificação do ponto de maturidade fisiológica é importante para definir o estágio de colheita de espécies colhidas manualmente (CARVALHO e NAKAGAWA, 2000). Ragagnin e Dias (1987) identificaram que as sementes de T. chrysotricha devem ser colhidas com 58,9\% de teor de água e 8 mg de peso de matéria seca por semente, para que se possa obter a máxima germinação $(96,6 \%)$.

Em sementes florestais, a definição do estágio de colheita torna-se muito importante, pois grande número de espécies produz frutos deiscentes (que se abrem na árvore para que ocorra a dispersão natural), que dificultam a coleta no solo (PIÑA-RODRIGUES e AGUIAR, 1993). No caso do gênero Tabebuia, esse cuidado é acentuado pela presença de asas, que favorecem a dispersão anemocórica. Além disso, na maioria das espécies a maturidade fisiológica é anterior à dispersão da semente (CARVALHO e NAKAGAWA, 2000).

No campo, para a colheita de sementes de espécies florestais são usualmente empregados aspectos físicos dos frutos, como cor, tamanho, cheiro e abertura espontânea, como referências para a identificação prática do estágio de colheita (SENA e GARIGLIO, 1998). Trabalhos de pesquisa, como o de Alves et al. (2004), indicam que também podem ser utilizados como referência os dias após a antese, mas essa é uma característica dependente das condições edafoclimáticas da região onde está localizada a planta-matriz e da genética da planta-mãe.

Germaque et al. (2002), estudando o ponto ideal de colheita de sementes de Tabebuia impetiginosa (Mart.) Standl., obtiveram maior germinação e vigor de sementes colhidas no início da deiscência dos frutos, quando estes apresentavam cor verde com pontos arroxeados e sementes de cor verde-amarelo-amarronzada e com teores de água de 69,02\% e 50,98\%, em frutos e sementes, respectivamente.

O substrato utilizado para testar a germinação das sementes também pode influenciar a porcentagem final de germinação devido à sua estrutura, aeração, capacidade de retenção de água e facilidade de infestação por patógenos, o que pode variar, dependendo do tipo de material utilizado (SCALON, 1992; ESCHIAPATIAFERREIRA e PEREZ, 1997; JELLER e PEREZ, 1999).

Souza et al. (2003) verificaram que o melhor substrato para a germinação de sementes de Tabebuia serratifolia (Vahl.) Nicholson foi a areia e a melhor temperatura, a de $30^{\circ} \mathrm{C}$. Segundo Machado et al. (2002), para essa espécie tanto o substrato areia quanto o papel são promissores para uso no teste de germinação de suas sementes, dentro da faixa ótima de temperatura $\left(25\right.$ a $\left.35^{\circ} \mathrm{C}\right)$.

A colheita de sementes que apresentam vigor e germinação altos é de reconhecida importância para produção de mudas com rapidez e eficiência, maximizando outros investimentos do setor. Assim, o objetivo deste trabalho foi identificar o estágio de colheita e o substrato mais favorável ao teste de germinação das sementes e crescimento de plântulas de Tabebuia chrysotricha.

\section{MATERIAL E MÉTODOS}

Os frutos de T. chrysotricha foram colhidos diretamente da copa em 16 árvores-matriz em 19/08/ 2003, no campus da UNESP - Faculdade de Ciências Agronômicas - Fazenda Experimental Lageado, em Botucatu, São Paulo. 
Foram avaliadas as seguintes características físicas dos frutos e das sementes no momento da colheita: i) coloração de frutos e sementes, identificados mediante a comparação com a carta de cores de Munsell (1976); ii) espessura, largura e comprimento dos frutos, mensurados com paquímetro e régua graduada de 30 $\mathrm{cm}$, respectivamente; iii) teor de água das sementes, determinado pelo método da estufa a $105 \pm 3^{\circ} \mathrm{C}$ por 24 h, com duas repetições por estágio de colheita (BRASIL, 1992).

Os frutos foram classificados em quatro estágios de colheita: fruto fechado menor (ME), fruto fechado maior (MA), fruto em início de abertura (IA) e fruto aberto e em início de dispersão das sementes (D).

Para avaliar o efeito do estágio de colheita e do substrato para germinação sobre a qualidade fisiológica das sementes, foram realizados o teste de germinação e os testes de vigor (primeira contagem do teste de germinação e comprimento de plântulas).

Para o teste de germinação foram testados dois substratos: sobre papel umedecido com duas vezes e meia o seu peso em água(BRASIL, 1992) e areia (semeadura sobre areia) de granulometria menor que $1,7 \mathrm{~mm}$, esterilizada em estufa a $120^{\circ} \mathrm{C}$ por $24 \mathrm{~h}$, e umedecida com água na quantidade de $60 \%$ da capacidade de retenção da areia (BRASIL, 1992), dentro de caixas plásticas transparentes (11 x 11 x 3,5 cm) sob temperatura constante de $25^{\circ} \mathrm{C}$, com $8 \mathrm{~h}$ de luz e $16 \mathrm{~h}$ de escuro, em germinador tipo câmara. As avaliações foram realizadas a cada sete dias até completar
21 dias, contabilizando-se a porcentagem de plântulas normais (germinação), anormais e sementes mortas ao final do período (BRASIL, 1992).

O teste da primeira contagem de germinação foi realizado, contabilizando-se a porcentagem de plântulas normais aos sete dias após a semeadura. O comprimento de plântulas $(\mathrm{cm})$ foi determinado, mensurando-se com régua o comprimento da raiz primária e da parte aérea e o comprimento total das plântulas após 21 dias da semeadura.

A análise estatística foi realizada em esquema fatorial $4 \times 2$ (quatro estágios de colheita e dois tipos de substrato), em delineamento inteiramente casualizado com quatro repetições de 50 sementes em cada tratamento, e as médias foram comparadas pelo teste de Tukey $(\mathrm{P}>0,05)$.

\section{RESULTADO E DISCUSSÃO}

As características físicas dos frutos e das sementes nos diferentes estágios de colheita são apresentadas no Quadro 1. Os estágios de colheita fruto fechado menor (ME), fruto fechado maior (MA) e fruto em início de abertura (IA) apresentaram largura e espessura similares. Os frutos colhidos com sementes em início de dispersão (D) não puderam ter esses parâmetros mensurados, devido às características do fruto que, totalmente aberto, impossibilitava a medição. Assim, a espessura e largura de frutos não puderam ser usadas para diferenciar nenhum dos estágios de colheita.

Quadro 1 - Características físicas dos frutos (dimensões e cor) e das sementes (cor e teor de água) nos estágios de colheita dos frutos de ipê (Tabebuia chrysotricha): fruto fechado menor (ME), fruto fechado maior (MA), fruto em início de abertura (IA) e fruto aberto e em início de dispersão (D)

Table 1 - Physical characteristics of fruit dimension and color) and seeds( color and water content) during the harvest stages of Tabebuia chrysotricha fruits: smaller closed fruit (ME); larger closed fruit (MA); initial opening fruit (IA) and open fruit with initial seed dispersion (D)

\begin{tabular}{|c|c|c|c|c|c|c|}
\hline \multirow{2}{*}{$\begin{array}{l}\text { Estágio de } \\
\text { Colheita }\end{array}$} & \multicolumn{3}{|c|}{ Dimensões do Fruto $(\mathrm{cm})$} & \multicolumn{2}{|r|}{ Cor (hue) ${ }^{1}$} & \multirow{2}{*}{$\begin{array}{r}\text { Teor de Água } \\
\text { das Sementes (\%) } \\
\end{array}$} \\
\hline & $\mathrm{E}$ & $\mathrm{L}$ & $\mathrm{C}$ & Fruto & Semente & \\
\hline ME & 0,8 & $\overline{1,1}$ & 17,6 & 2,5 Y $4 / 6$ & $10 \mathrm{Y} 6 / 4$ e $7 / 6$ & $70,1 \mathrm{a}$ \\
\hline MA & 0,9 & 1,3 & 29,4 & 2,5 Y $4 / 6$ & $\begin{array}{l}\text { Bordas: } 2,5 \text { Y 5/4; 7/4; } 6 / 6 \text { e } 7 / 6 \\
\text { Centro: } 7,5 \text { YR 3/6 e 3/4 }\end{array}$ & 66,3 b \\
\hline IA & 0,7 & 1,1 & 26,9 & 2,5 Y 4/6 & 7,5 YR 2/4; 3/4; 4/4 e 3/6 & 59,6 c \\
\hline $\mathrm{D}$ & - & - & 26,2 & 2,5 Y $4 / 6$ & 7,5 YR 2/4; 3/4; 4/4 e 3/6 & $\begin{array}{c}41,0 \mathrm{~d} \\
\mathrm{CV}(\%)=1,74\end{array}$ \\
\hline
\end{tabular}

E: espessura, L: largura e C: comprimento.

${ }^{1}$ Unidade de cor, nos matizes de amarelo (Y) e amarelo-avermelhado (YR), segundo a classificação da carta de cores de Munsell (1976). ${ }^{2}$ Médias seguidas da mesma letra minúscula na coluna e maiúscula na linha não diferem estatisticamente entre si, de acordo com o teste de Tukey $(\mathrm{P}>0,05)$

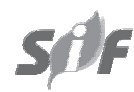

R. Árvore, Viçosa-MG, v.32, n.1, p.27-32, 2008 
Para diferenciar os estágios de colheita de frutos menor (ME) e maior (MA), pode ser usado o comprimento, havendo uma diferença de aproximadamente $12 \mathrm{~cm}$ no comprimento dos frutos colhidos num e noutro estágio, facilmente identificável no campo. Os frutos em início de abertura (IA) e em dispersão (D) apresentaram comprimento similar e superior $(\simeq 8,9 \mathrm{~cm})$ que os colhidos nos estágios menor (ME) e inferior $(\simeq 2,5 \mathrm{~cm})$ àqueles colhidos no estágio maior (MA). Assim, para diferenciar os frutos em início de abertura (IA) e em dispersão (D), mais importante do que medir o comprimento seria observar o aspecto externo do fruto quanto à deiscência e dispersão para estabelecer, com maior certeza, esses estágios de colheita.

A cor dos frutos em todos os estágios de colheita foi amarelo-amarronzada (2,5 Y 4/6) e, por isso, apresentouse como referência ineficiente para diferenciá-los e ser usada para a identificação prática do estágio de colheita da espécie T. chrysotricha, embora para outras espécies possa ser usada (SENA e GARIGLIO, 1998; GERMAQUE et al., 2002).

As sementes apresentaram mais de uma cor em cada estágio de colheita. As sementes colhidas em fruto menor (ME) apresentaram dois tons de verde claro-amarelado (10Y 6/4 e 7/6). As colhidas em fruto maior (MA) apresentaram-se com as bordas mais claras, em quatro tons de verde-claro amarelado (2,5 Y 5/4; 7/4; 6/6 e 7/6), e o centro escuro, em dois tons amarronzados (7,5 YR 3/6 e 3/4). As combinações das cores das bordas e do centro das sementes foram variadas. Os frutos em início de abertura (IA) e em dispersão (D) apresentaram sementes com as mesmas cores, em quatro tons amarronzados (7,5 YR 2/4;3/4; 4/4; e3/6), dois deles idênticos aos apresentados pelo centro das sementes (que apresentam asas hialinas) colhidas no estágio fruto maior (MA). Assim, as cores das sementes podem ser usadas para identificar as sementes colhidas nos estágios de fruto menor (ME) e fruto maior (MA), mas não possibilitam diferenciar as sementes colhidas de frutos em início de abertura (IA) e em início de dispersão (D).

O teor de água das sementes foi um parâmetro capaz de distinguir, de forma significativa, os estágios de colheita das sementes, apresentando valores menores quanto mais adiantado o estágio de maturação e mais próximo o momento de dispersão. O teor de água de $41 \%$ encontrado nas sementes de ipê em estágio de dispersão ainda pode ser considerado relativamente alto, se comparado com a maioria das sementes de

R. Árvore, Viçosa-MG, v.32, n.1, p.27-32, 2008 espécies vegetais, pois sementes mantidas com teores de água entre 30 e $50 \%$ após a maturidade fisiológica podem sofrer deterioração ou germinação na própria planta (CARVALHO e NAKAGAWA, 2000). Sementes de $T$. serratifolia têm de ser secadas até $8 \%$ de teor de água para poder ser armazenadas sem perder a qualidade devido à deterioração (SOUZA et al., 2005). A fim de evitar esses eventos indesejáveis para a perpetuação da espécie, os ipês dispõem de um mecanismo de redução rápida do teor de água das sementes, que é a deiscência dos frutos.

O substrato areia foi mais favorável ao processo de germinação que o substrato papel, possibilitando as sementes originar maior número de plântulas normais, o que pôde ser visto na porcentagem final de germinação, e mais rapidamente, o que foi verificado pelo teste da primeira contagem. Esses efeitos foram constatados em todos os estágios de colheita avaliados (Quadro 2). Adicionalmente, o substrato areia favoreceu o crescimento da raiz das plântulas, exceto no estágio de colheita em dispersão (D), que não foi afetado pelo substrato. Particularmente, as sementes colhidas no estágio início de abertura (IA) também apresentaram maior parte aérea de plântulas quando semeadas em areia (Quadro 2). A menor porcentagem de germinação em papel ocorreu em função da maior mortalidade das sementes nesse substrato. Houve interação significativa entre os fatores estágios de colheita e substrato somente nas características relacionadas ao comprimento das plântulas, quanto à parte aérea e raiz (Quadro 2).

No substrato areia houve maior índice de plântulas anormais e menor número de sementes mortas. A maior porcentagem de plântulas anormais foi verificada nas sementes provenientes de fruto menor, porém diferindo significativamente apenas das sementes de fruto maior. Souza et al. (2003) também verificaram que o melhor substrato para a germinação de sementes de $T$. serratifolia foi a areia. No entanto, Machado et al. (2002) não notaram diferenças de germinação em ambos os substratos. Neste trabalho, observou-se maior incidência de fungos nas sementes e plântulas quando se utilizou o substrato papel, o que parece ter causado maior porcentagem de sementes mortas. Dessa forma, o substrato areia mostra-se mais indicado para a condução do teste de germinação de sementes de ipê, confirmando resultados obtidos por Souza et al. (2003) nesse mesmo gênero. $\mathrm{O}$ substrato areia minimiza o ataque de fungos 
na germinação, havendo recomendação de sua utilização quando a avaliação do teste de germinação for impraticável por excesso de infecção (BRASIL, 1992). Em sementes de algodão deslintado mecanicamente, a areia acarreta menores variações e reduz a quantidade de plântulas anormais infeccionadas, mostrando-se mais favorável à germinação que o papel-toalha (NOVEMBRE e MARCOS-FILHO, 1999).

Entre os estágios de colheita testados, o mais favorável ao processo de germinação foi o dos frutos em início de abertura (IA). Esse apresentou sementes com as maiores porcentagens de germinação e menores porcentagens de sementes mortas em ambos os substratos utilizados, bem como maior velocidade no processo, verificado pelo teste da primeira contagem, significativamente superior às dos demais estágios de colheita, que não diferiram entre si. Da mesma forma, a maturidade fisiológica das sementes, que é anterior à dispersão de $T$. serratifolia, também foi verificada em sementes de Mimosa caesalpiniifolia Benth. (ALVES et al., 2004) e Tabebuia impetiginosa (GERMAQUE et al., 2002). Os resultados são similares aos obtidos em Tabebuia impetiginosa, que apresentou sementes com máxima germinação e vigor quando os frutos foram colhidos por ocasião do início da deiscência (GERMAQUE et al., 2002), embora outras características físicas que identificam esse estágio de colheita, citadas no referido trabalho, como cor de fruto e de semente e teor de água, tenham sido diferentes dos obtidos em $T$. chrysotricha, fato que pode ter ocorrido por se tratar de espécies distintas do gênero Tabebuia.

Quadro 2 - Resultados médios de germinação, plântulas anormais, sementes mortas, primeira contagem da germinação e comprimento de plântula (parte aérea e raiz), em função do substrato e dos seguintes estágios de colheita dos frutos de ipê (Tabebuia chrysotricha): fruto fechado menor (ME), fruto fechado maior (MA), fruto em início de abertura (IA) e fruto aberto e em início de dispersão das sementes (D)

Table 2 - Mean results of germination, abnormal seedlings, dead seeds, first count of germination test and seedling length (shoot and root) as affected by substratum and the following harvest stages of Tabebuia chrysotricha fruit: smaller closed fruit (ME); larger closed fruit (MA); initial opening fruit (IA) and open fruit with initial seed dispersal (D)

\begin{tabular}{|c|c|c|c|c|c|c|c|c|c|c|c|c|}
\hline \multirow{3}{*}{$\begin{array}{l}\text { Estágio de } \\
\text { Colheita }\end{array}$} & \multirow{2}{*}{\multicolumn{2}{|c|}{$\begin{array}{c}\text { Germinação } \\
(\%)\end{array}$}} & \multirow{2}{*}{\multicolumn{2}{|c|}{$\begin{array}{c}\text { Anormais } \\
(\%)\end{array}$}} & \multirow{2}{*}{\multicolumn{2}{|c|}{$\begin{array}{c}\text { Mortas } \\
(\%)\end{array}$}} & \multirow{2}{*}{\multicolumn{2}{|c|}{$\begin{array}{c}\text { Primeira } \\
\text { Contagem (\%) }\end{array}$}} & \multicolumn{4}{|c|}{ Comprimento de Plântula (cm) } \\
\hline & & & & & & & & & \multicolumn{2}{|c|}{ Parte Aérea } & \multicolumn{2}{|c|}{ Raiz } \\
\hline & Papel & Areia & Papel & Areia & Papel & Areia & Papel & Areia & Papel & Areia & Papel & Areia \\
\hline ME & $48,0 \mathrm{bB}$ & $51,0 \mathrm{bA}$ & $1,5 \mathrm{aB}$ & $4,5 \mathrm{aA}$ & $50,5 \mathrm{aA}$ & $44,5 \mathrm{aB}$ & $23,0 \mathrm{bB}$ & $30,0 \mathrm{bA}$ & $1,1 \mathrm{aA}$ & $1,3 \mathrm{bA}$ & $1,2 \mathrm{bB}$ & $2,2 \mathrm{aA}$ \\
\hline MA & $52,5 b B$ & $57,0 \mathrm{bA}$ & $0,0 \mathrm{bB}$ & $0,0 \mathrm{bA}$ & $47,5 \mathrm{aA}$ & $43,0 \mathrm{aB}$ & $24,0 \mathrm{bB}$ & $31,0 \mathrm{bA}$ & $1,2 \mathrm{aA}$ & $0,9 \mathrm{cA}$ & $1,1 \mathrm{bB}$ & $1,6 \mathrm{bA}$ \\
\hline IA & $67,0 \mathrm{aB}$ & $71,0 \mathrm{aA}$ & 1,0abB & 3,0abA & $34,5 \mathrm{bA}$ & $26,0 \mathrm{bB}$ & $42,0 \mathrm{aB}$ & $43,0 \mathrm{aA}$ & $1,4 \mathrm{aB}$ & $1,8 \mathrm{aA}$ & $1,3 \mathrm{bB}$ & $2,4 \mathrm{aA}$ \\
\hline $\mathrm{D}$ & $46,0 \mathrm{bB}$ & $53,5 \mathrm{bA}$ & $0,0 \mathrm{abB}$ & 2,0abA & $54,0 \mathrm{aA}$ & $44,5 \mathrm{aB}$ & $20,0 \mathrm{bB}$ & $36,0 \mathrm{bA}$ & $1,4 \mathrm{aA}$ & 1,5abA & 2,0aA & $2,2 \mathrm{aA}$ \\
\hline CV(\%) & \multicolumn{2}{|c|}{7,14} & \multicolumn{2}{|c|}{53,32} & \multicolumn{2}{|c|}{10,43} & \multicolumn{2}{|c|}{11,40} & \multicolumn{2}{|c|}{13,90} & \multicolumn{2}{|c|}{13,01} \\
\hline
\end{tabular}

${ }^{1}$ Médias seguidas da mesma letra minúscula na coluna e maiúscula na linha não diferem estatisticamente entre si, de acordo com o teste de Tukey $(\mathrm{P}>0,05)$.

\section{CONCLUSÕES}

As sementes de Tabebuia chrysotricha devem ser colhidas quando o fruto estiver em início de abertura, para a obtenção de sementes com máxima germinação e vigor.

O estágio de colheita do fruto em início de abertura também pode ser identificado pelo teor de água das sementes de $59,6 \%$.

O substrato areia é o mais favorável ao teste de germinação e ao crescimento das plântulas de $T$. chrysotricha.

\section{REFERÊNCIAS}

ALVES, E. U. et al. Dormência e desenvolvimento de sementes de sabiá (Mimosa caesalpiniifolia Benth.). Revista Árvore, v.28, n.5, p.655-662, 2004.

BRASIL - Ministério da Agricultura e Reforma Agrária. Regras para análise de sementes. Brasília: SNDA/DNDV/CLAV, 1992. 365p.

CARVALHO, N. M.; NAKAGAWA, J. Sementes: ciência, tecnologia e produção. Jaboticabal: FUNESP, 2000. 588p. 
ESCHIAPATIA-FERREIRA, M. S.; PEREZ, S. C. J. A. Tratamento para superar a dormência de semente de Senna macranthera (Collad.) Irwing et Bran. (Fabaceae- Caesalpinoidea). Revista Brasileira de Sementes, v.19, n.2, p.231-237, 1997.

GERMAQUE, R. C. R.; DAVIDE, A. C.; FARIA, J. M. R. Indicadores de maturidade fisiológica de sementes de Ipê-roxo (Tabebuia impetiginosa (Mart.) Standl.). Cerne, v.8, n.2, p.84-91, 2002.

JELLER, H.; PEREZ, S. C. J. A. Estudo da superação da dormência e da temperatura de semente de Cassia excelsa. Revista Brasileira de Sementes, v.21, n.1, p.32-40, 1999.

LORENZI, H. Árvores brasileiras: manual de identificação e cultivo e de plantas arbóreas nativas do Brasil. Nova Odessa: Plantarum, 1992. 368p.

MACHADO, C. F. et al. Metodologia para a condução do teste de germinação em sementes de ipê-amarelo (Tabebuia serratifolia (Vahl.) Nicholson). Cerne, v.8, n.2, p.17-25, 2002.

MUNSELL, A. H. Munsell book of color. Maryland: Macbeth Division of kollmorgen instruments corporation. v.2.5 BG-10 RP/ 2,5R10G, 1976. (folhas avulsas).

NOVEMBRE, A. D. L. C.; MARCOS-FILHO, J. Estudo da metodologia para condução do teste de germinação em sementes de algodão deslintadas mecanicamente. Revista Brasileira de Sementes, v.21, n.2, p.187-193, 1999.
PIÑA-RODRIGUES, F. C. M.; AGUIAR, I. B. Maturação e dispersão de sementes. In: AGUIAR, I. B.; PIÑA-RODRIGUES, F. C. M.; FIGLIOLIA, M. B. Sementes florestais tropicais. Brasília: ABRATES,1993. p.215-274.

RAGAGNIN, L. I. M.; DIAS, L. L. Maturação fisiológica de sementes de Tabebuia chrysotricha In: CONGRESSO BRASILEIRO DE SEMENTES, 5., 1987, Gramado. Resumos... Gramado: 1987. p.128.

SCALON, S. P. Q. Estudo da germinação de sementes e produção de mudas de pau-pereira (Platycyamus regnelli Benth.). 1992. 63f. Dissertação (Mestrado em...) - Escola Superior de Agricultura de Lavras, Lavras, 1992.

SENA, C. M.; GARIGLIO, M. A. Sementes florestais: colheita, beneficiamento e armazenamento. Brasília: IBAMA, 1998. 26p.

SOUZA M. A S. M.; RAMOS, M. B. P.; VARELA, V. P. Influência da temperatura e do substrato na germinação de sementes de ipê-amarelo (Tabebuia serratifolia (Vahl.) Nich) In: CONGRESSO NACIONAL DE BOTÂNICA, 54.; REUNIÃO AMAZÔNICA DE BOTÂNICA, 3., 2003, Belém. Resumos... Belém: Universidade da Amazônia, 2003

SOUZA, V. C.; BRUNO, R. L. A.; ANDRADE, L. A. Vigor de sementes armazenadas de ipê-amarelo Tabebuia serratifolia (Vahl.) Nich. Revista Árvore, v.29, n.6, p.833-841, 2005. 